\title{
Accuracy of parent-reported information for estimating prevalence of overweight and obesity in a race-ethnically diverse pediatric clinic population aged 3 to 12
}

Nancy P Gordon ${ }^{1 *}$ and R Grant Mellor ${ }^{2}$

\begin{abstract}
Background: There is conflicting evidence about the accuracy of estimates of childhood obesity based on parentreported data. We assessed accuracy of child height, weight, and overweight/obesity classification in a pediatric clinic population based on parent data to learn whether accuracy differs by child age and race/ethnicity.

Methods: Parents of patients ages 3-12 $(n=1,119)$ completed a waiting room questionnaire that asked about their child's height and weight. Child's height and weight was then measured and entered into the electronic health record (EHR) by clinic staff. The child's EHR and questionnaire data were subsequently linked. Accuracy of parentreported height, weight, overweight/obesity classification, and parent perception of child's weight status were assessed using EHR data as the gold standard. Statistics were calculated for the full sample, two age groups (3-5, 6-12), and four racial/ethnic groups (nonHispanic White, Black, Latino, Asian).

Results: A parent-reported height was available for $59.1 \%$ of the children, weight for $75.6 \%$, and weight classification for $53.0 \%$. Data availability differed by race/ethnicity but not age group. Parent-reported height was accurate for $49.2 \%$ of children and weight for $58.2 \%$. Latino children were less likely than nonHispanic Whites to have accurate height and weight data, and weight data were less accurate for 6-12 year than 3-5 year olds. Concordance of parent- and EHR-based classifications of the child as overweight/obese and obese was approximately $80 \%$ for all subgroups, with kappa statistics indicating moderate agreement. Parent-reported data significantly overestimated prevalence of overweight/obesity (50.2\% vs. $35.2 \%)$ and obesity (32.1\% vs. $19.4 \%)$ in the full sample and across all age and racial/ethnic subgroups. However, the percentages of parents who perceived their child to be overweight or very overweight greatly underestimated actual prevalence of overweight/obesity and obesity. Missing data did not bias parent-based overweight/obesity estimates and was not associated with child's EHR weight classification or parental perception of child's weight.
\end{abstract}

Conclusions: While the majority of parents of overweight or obese children tend to be unaware that their child is overweight, use of parent-reported height and weight data for young children and pre-teens will likely result in overestimates of prevalence of youth overweight and obesity.

\footnotetext{
* Correspondence: nancy.gordon@kp.org

${ }^{1}$ Division of Research, Kaiser Permanente Medical Care Program, 2000

Broadway, Oakland, CA 94611, USA

Full list of author information is available at the end of the article
} 


\section{Background}

Childhood obesity is a risk factor for childhood and adult chronic diseases [1,2]. According to population health surveys, the youth obesity rate in the United States has nearly tripled over the last two decades, although it has recently shown signs of leveling off [3]. For cost and logistical reasons, national and state population health surveillance tools that are used to monitor, research, and formulate policy regarding childhood overweight and obesity rely on parent report of a child's height and weight to create estimates of obesity prevalence. However, there has been little assessment of the accuracy of these statistics for the 3- to 12-year-old age span that reflects the population for most pediatric clinic and school-based obesity intervention efforts. The accuracy of parent-reported height and weight data also has implications for non-surveillance purposes, e.g., identification of children at risk for obesity and obesity-related chronic conditions based on health assessment questionnaires and pediatric obesity-related research and program evaluation.

Published studies of the accuracy of proxy reports of child height, weight, and obesity status have shown that parent-reported values for classifying children as overweight or obese have relatively poor accuracy, including both overestimates and underestimates of overweight and obesity [4-15]. Most of those studies focused on accuracy of weight classification and did not provide information about the accuracy of parent-reported height and weight as separate outcomes, and most did not examine multi-ethnic populations. Given current policy concerns about childhood overweight and obesity, it is important to learn about the accuracy of parent-based information and to learn whether parents have tools at home that can be used to provide more accurate measurements of child height and weight for surveys and research studies upon request.

To assess the accuracy of parent-reported information about child's height and weight and overweight/obesity classification based on that information, in 2013 we conducted a waiting-room survey with a convenience sample of parents of children ages 3 to 12 in an outpatient clinic of a Northern California health plan. The children were going to have their height and weight measured that day as a routine part of their pediatric visit. The study assessed: (1) Accuracy of parent-reported child height, weight, and resulting overweight/obese and obese classifications in children ages 3 to 12 , with clinicmeasured height, weight, and overweight/obese and obese classifications as the standard; (2) Factors associated with accuracy of parent-reported data; (3) Accuracy of parents' perceptions about whether their children are overweight; (4) Factors associated with missing weight classification data and the extent to which missing weight classification data introduces bias into overweight/obesity estimates; (5) Availability of tools at home (scale, tape measure) to measure a child's height and weight if asked to do so; and (6) Whether assessments 1-5 differ by children's age group and race/ethnicity.

\section{Methods}

\section{Data source}

This study was implemented in three Kaiser Permanente Northern California pediatric clinics (Stockton, Vallejo, and Fairfield) that serve a race-ethnically diverse population that is primarily working and middle class. All three clinics routinely measure height and weight at every pediatric appointment. From January to April 2013, pediatric department receptionists and medical assistants handed out a brief (13 item) paper questionnaire in English or Spanish to all parents of pediatric patients ages 3 to 12 at time of registration for the visit. The receptionists asked parents of age-eligible patients if they would be willing to fill out a very short questionnaire about their child's height and weight while they were in the waiting room and mentioned a small thank-you gift they would receive. If the parent agreed, the receptionist put the pediatric patient's name, health plan number, and appointment date on the questionnaire and handed it to the parent on a clipboard. Parents were told to return their completed questionnaire to the receptionist or medical assistant before their child was weighed and measured, at which time they would receive the gift.

Parents were informed at the top of the questionnaire that the study was being done to learn how accurate parents are when they are asked to report their child's height and weight in surveys and to medical staff during phone consults, and that their answers would be linked to their child's height and weight measured by the medical assistant. The questionnaire (see Additional file 1) asked for the child's age, sex, height (in feet/inches or meters/centimeters), weight (in pounds/ounces or kilograms/grams), the last time the parent found out the child's height and weight, parent's perception of the child's weight (underweight, about right, overweight, or very overweight), and whether they had a scale and a tape measure or yard stick at home that could be used to weigh and measure the child if they were asked to do so.

At each site, point-of-service staff were trained in the data collection procedures and monitored by the Pediatric department manager or Pediatric Chief. Medical assistants were instructed not to give parents who were participating in the study access to the child's clinic-measured height and weight until after the questionnaire was collected. Data collection lasted 2 to 3 consecutive weeks at each site, at which time completed questionnaires were sent to the Study Director. 
Questionnaire data were subsequently linked with height, weight, and body mass index (BMI) measurements from the child's electronic health record (EHR) at that visit, as well as age, sex, and race/ethnicity. The study protocol was approved by Kaiser Permanente Northern California Region's Institutional Review Board.

\section{Statistical analysis}

BMI-for-age percentiles based on child's height, weight, age, and gender were calculated from parent-reported and EHR data by using SAS code available from the Centers for Disease Control (CDC) [16]. Individual differences between parent-reported and EHR values for height, weight, and BMI-for-age percentile were calculated by subtracting the EHR value from the parentreported value. Parent-reported data was considered to be accurate when reported height was within \pm 1 inch of the EHR height, weight was within \pm 2 lbs. of the EHR weight, and BMI-for-age percentile was within \pm 5 percentage points of EHR BMI-for-age percentile. Based on their BMI-for-age percentile, children were classified as not overweight (1st-84th percentile), overweight/obese ( $\geq 85$ th percentile), or obese ( $\geq 95$ th percentile). Children with a BMI-for-age percentile $<1$, which usually results from a biologically implausible height, weight, or heightweight combination, were not assigned a weight classification following CDC recommendations [16]. Accuracy of overweight/obese and obese classification based on parent-reported and EHR data was assessed using kappa statistics [17]. Using EHR weight classification as a "gold standard", we calculated sensitivity (probability that a child who is overweight/obese or obese is accurately classified as such based on parent-reported data), specificity (probability that child who is not overweight/obese or obese is accurately classified as such based on parentreported data), and positive predictive value (probability that a child who is classified as overweight/obese or obese based on parent-reported data was accurately classified). We compared prevalence of overweight/obesity and obesity based on EHR data (all children and children with a parent report-based weight classification), on parent-reported data (for children with a usable BMIfor-age percentile), and parent perception of whether the child was overweight in the full sample, two age groups ( 3 to 5 years and 6 to 12 years), and four racial and ethnic groups (nonHispanic White, Black, Latino, and Asian).

Because $32 \%$ to $56 \%$ of children in different age and race-ethnic subgroups had insufficient parent-reported data to assign a weight classification, we also assessed whether missing parent-reported data biased prevalence estimates of overweight/obesity and obesity for the full sample and different demographic subgroups. To do this, we compared the EHR-based prevalence of overweight/obesity and obesity for groups of children who did and did not have a usable weight classification based on parent-reported data. We also re-estimated parent report-based prevalence of overweight/obesity and obesity using a post-stratification weighting factor that made the sample of children with parent reportbased weight classification reflect the actual age group (3 to 5, 6 to 9, 10 to 12), sex, and racial/ethnic distribution of the full sample [18]. Finally, to examine factors associated with missing weight classification data, we compared children with and without parent reportbased weight classification on parent perception that their child was overweight; length of time since child's most recent height and weight measurements; parent who completed the questionnaire; and where relevant, child's sex, age group, and race/ethnicity.

An online statistics program [19] was used to calculate kappa, sensitivity, specificity, positive predictive value using data from $2 \times 2$ tables. All other statistical analyses were performed using SAS version 9.3 [20]. Chi-square tests were used to assess whether differences between age groups ( 3 to 5 vs. 6 to 12) and between nonHispanic Whites and each of the other race/ethnic groups on categorical variables were statistically significant. Twotailed z-tests for proportions were used to test for differences between prevalence of overweight/obesity and obesity based on EHR data for the full sample and parent-reported data, and two-tailed t-tests were used to compare means and mean differences. Multivariable logistic regression and general linear models were used to assess independent association of demographic and other factors with accuracy of parent-reported data. Unless otherwise specified, differences cited in the text as statistically significant met the $P<.05$ threshold. We did not adjust $P$-values for multiple comparisons, but the results of all planned race-ethnicity and age group comparisons are reported in the tables or text.

\section{Results}

\section{Study sample characteristics}

Questionnaires were collected for 1,119 children aged 3 to 12 . However, 67 (6\%) of these were later excluded due to the questionnaire having been completed by a nonparent/guardian $(\mathrm{n}=39)$, too much missing information $(\mathrm{n}=13)$, medical record number that couldn't be matched to an appointment $(\mathrm{n}=1)$, no height in the child's EHR for the date on the questionnaire $(n=3)$, or implausible $(<1$ st) EHR-derived BMI-for-age percentile $(\mathrm{n}=11)$. This left information for 1,053 children, 434 aged 3 to 5 (210 boys, 224 girls) and 619 aged 6 to 12 (313 boys, 306 girls). Of the 1,021 children (97\%) who could be matched to a race/ethnicity, $27.0 \%$ were nonHispanic White $(\mathrm{n}=276), 11.4 \%$ African-American/ Black $(n=116), 40.1 \%$ Hispanic/Latino $(n=409), 19.3 \%$ 
Asian $(\mathrm{n}=197)$, and 5.2\% Other $(\mathrm{n}=55)$. The racial/ethnic composition of the two age groups and the age-gender group distribution within the race-ethnic groups were not significantly different. Most (84.6\%) of the questionnaires were completed by a mother, with the rest completed by a father (15.3\%) or other guardian (0.1\%).

\section{Completeness of parent-reported data}

Of the 1,053 children with complete EHR data, 59.1\% had a parent-reported height, $75.6 \%$ had a parentreported weight, $56.3 \%$ had both height and weight, and $21.6 \%$ had neither (Table 1 ). Only $53 \%$ of children had usable BMI-for-age percentile for assignment to a weight classification after 35 (3\%) of children were excluded due to having a value below the 1st percentile.

Availability of parent-reported height and weight data and usable BMI-for-age percentile did not significantly differ by child age group. However, compared to parents of nonHispanic White children, parents of Black, Latino and Asian children were significantly less likely to report their child's weight, and parents of
Latino and Asian children were significantly less likely to report a height. This resulted in significantly lower percentages of Latino (45\%) and Asian (43\%) children compared to nonHispanic White children (68\%) for whom a BMI-for-age percentile could be calculated and weight classification assigned based on parentreported data.

As shown in Table 1, approximately $47 \%$ of parents indicated they last learned their child's weight within the past month, but for nearly $20 \%$ of parents it had been over 6 months. Similarly, 34\% had learned their child's height within the past month, but for nearly $30 \%$ it had been over 6 months. Parents of children aged 6 to 12 were significantly more likely than parents of children aged 3 to 5 to indicate that these measurements had last occurred more than six months ago. As the length of time since last known measurements increased (in past 7 days, $>7$ days but within past month, $>1$ month but within past 6 months, more than 6 months ago), there were statistically significant declines in the percentages of parents who reported child weight $(93.8 \%, 86.2 \%, 73.3 \%$,

Table 1 Availability of parent-reported child height and weight data, when parents recall last obtaining these measures, and source of parent report

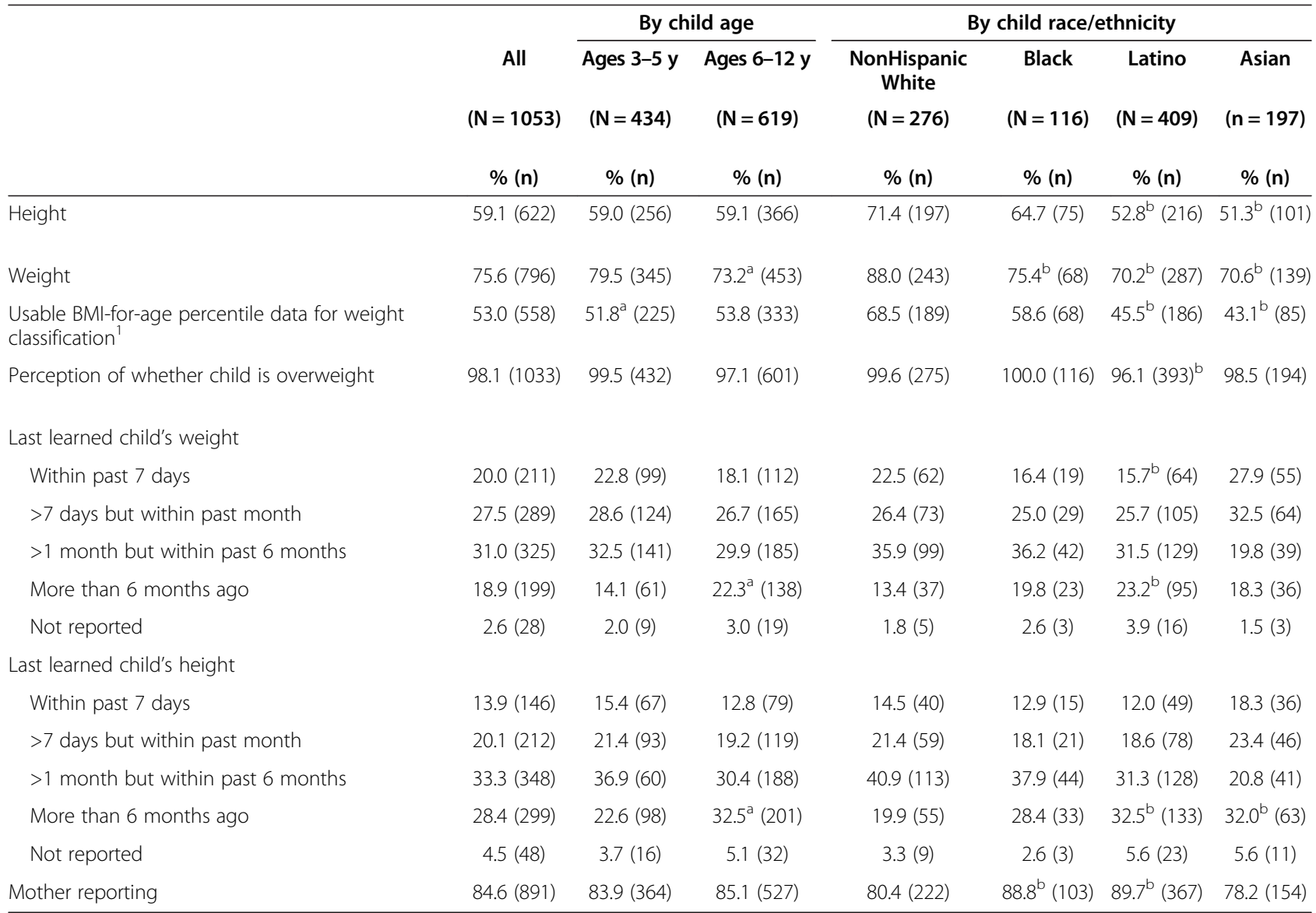

${ }^{1}$ BMI-for-age percentiles $<1$ were considered biologically implausible values and excluded from weight classification analyses.

${ }^{a}$ Significantly different from 3 to 5 year olds by chi-square test $(P<.05)$.

${ }^{\mathrm{b}}$ Significantly different from nonHispanic Whites by chi-square test $(P<.05)$. 
and $43.7 \%$, respectively), height $(84.2 \%, 70.9 \%, 62.6 \%$, and $37.1 \%$, respectively), and sufficient information to categorize the child as overweight/obese or obese $(79.5 \%$, $63.7 \%, 54.6 \%$, and $33.1 \%$, respectively). About $18 \%$ of parents said their child had grown a lot taller since his/her height was last measured, with no significant difference by child age or gender (data not shown).

\section{Accuracy of parent-reported information for height, weight, and obesity classification}

Measures of the accuracy of parent-reported height and weight and calculated BMI-for-age percentile and classification as overweight or obese are shown in Table 2. Parent-reported child height was within 1 inch of EHR height for $49 \%$ of children and parent-reported child weight was within 2 lbs. of the EHR weight for slightly under $60 \%$ of children. Errors for both height and weight were more often due to underestimation than overestimation. Approximately 35\% of parents (220/662) underestimated actual height by at least 1 inch and $26 \%$ by at least 2 inches (mean height difference of $-1.10, \mathrm{SD}=3.70$ ), with no significant difference by age group. About $22 \%$ $(74 / 343)$ of parents of children aged 3 to 5 and $39 \%$ $(175 / 452)$ of parents aged 6 to 12 underestimated their child's weight by at least 2 lbs., with mean weight difference significantly smaller for the younger versus older children (-0.73 (SD 3.14) vs. -2.06 (SD 6.75), $P<.0001)$. BMI-for-age percentile based on parent report was within \pm 5 percentiles for approximately 46\% (259/558) of children, but accuracy was significantly higher for

Table 2 Accuracy of parent-reported data for child height, weight, BMI-for-age percentile, and weight classification as compared to electronic health record data

\begin{tabular}{|c|c|c|c|c|c|c|c|}
\hline \multirow{4}{*}{ Accuracy of parent-reported data } & \multirow{4}{*}{$\begin{array}{c}\text { All } \\
\% \\
\% \\
(\mathrm{~N}=622)\end{array}$} & \multicolumn{2}{|c|}{ By child age } & \multicolumn{4}{|c|}{ By child race/ethnicity } \\
\hline & & \multirow{3}{*}{$\begin{array}{c}\text { Age } 3-5 y \\
\% \\
(N=256)\end{array}$} & \multirow{3}{*}{$\begin{array}{c}\text { Age 6-12 y } \\
\% \\
(N=366)\end{array}$} & \multirow{3}{*}{$\begin{array}{c}\text { NonHispanic } \\
\text { White } \\
\% \\
(\mathrm{~N}=197)\end{array}$} & \multirow{3}{*}{$\begin{array}{c}\text { Black } \\
\% \\
(\mathrm{~N}=75)\end{array}$} & \multirow{3}{*}{$\begin{array}{c}\text { Latino } \\
\% \\
\% \\
(\mathrm{~N}=216)\end{array}$} & \multirow{3}{*}{$\begin{array}{c}\text { Asian } \\
\% \\
\text { (N= 101) }\end{array}$} \\
\hline & & & & & & & \\
\hline & & & & & & & \\
\hline Height $^{1}$ Within \pm 1 inch of EHR height & 49.2 & 46.1 & 51.4 & 52.8 & 50.7 & $42.6^{b}$ & 53.5 \\
\hline Underestimates EHR height by $>1$ inch & 35.4 & 36.3 & 34.7 & 34.0 & 41.3 & 37.0 & 31.7 \\
\hline Overestimates EHR height by $>1$ inch & 17.6 & 17.6 & 13.9 & 13.2 & 8.0 & 20.4 & 14.8 \\
\hline $\begin{array}{l}\text { Mean (SD) difference of parent-reported vs. EHR } \\
\text { height }\end{array}$ & $-1.1(3.7)$ & $-1.0(3.7)$ & $-1.2(3.7)$ & $-0.8(2.9)$ & $-2.1^{b}(3.9)$ & $-1.3(4.4)$ & $-1.0(3.2)$ \\
\hline Weight $^{1}$ & $(\mathrm{~N}=796)$ & $(\mathrm{N}=343)$ & $(\mathrm{N}=452)$ & $(\mathrm{N}=241)$ & $(\mathrm{N}=87)$ & $(\mathrm{N}=287)$ & $(N=139)$ \\
\hline Within \pm 2 lbs. of EHR weight & 58.2 & 68.2 & $50.7^{a}$ & 60.6 & 59.8 & $51.6^{b}$ & 62.6 \\
\hline Underestimates EHR weight by > 2 lbs. & 31.3 & 21.6 & $38.6^{\mathrm{a}}$ & 28.6 & 31.0 & $37.9^{b}$ & 25.9 \\
\hline Overestimates EHR weight by > 2 lbs. & 10.4 & 10.2 & 10.8 & 10.8 & 9.2 & 10.2 & 11.5 \\
\hline $\begin{array}{l}\text { Mean (SD) difference of parent-reported vs. EHR } \\
\text { weight }\end{array}$ & $-1.5(6.4)$ & $-0.7(3.1)$ & $-2.1^{\mathrm{a}}(8.1)$ & $-0.9(7.5)$ & $-2.0(5.1)$ & $-2.2^{b}(5.6)$ & $-1.1(5.4)$ \\
\hline BMI-for-age percentile ${ }^{1}$ & $(\mathrm{~N}=558)$ & $(\mathrm{N}=225)$ & $(\mathrm{N}=333)$ & $(N=189)$ & $(N=68)$ & $(\mathrm{N}=186)$ & $(N=85)$ \\
\hline Within \pm 5 percentile pts. of EHR & 46.4 & 35.5 & $53.8^{d}$ & 40.8 & $55.9^{b}$ & 47.3 & 47.1 \\
\hline Underestimates EHR by $>5$ percentiles & 19.0 & 19.6 & 18.6 & 25.9 & $8.8^{b}$ & $17.2^{b}$ & 17.6 \\
\hline Overestimates EHR by $>5$ percentiles & 34.4 & 44.9 & $27.6^{d}$ & 33.3 & 35.3 & 35.5 & 35.3 \\
\hline $\begin{array}{l}\text { Mean (SD) difference of parent-report vs. EHR-based } \\
\text { BMI-for-age percentile }\end{array}$ & $5.5(26.5)$ & $9.7(30.4)$ & $2.7^{\mathrm{a}}(23.2)$ & $3.1(25.2)$ & $10.7^{\mathrm{b}}(27.3)$ & $5.1(26.6)$ & $7.1(29.4)$ \\
\hline Weight classification ${ }^{1}$ & $(\mathrm{~N}=558)$ & $(\mathrm{N}=225)$ & $(\mathrm{N}=333)$ & $(N=189)$ & $(N=68)$ & $(N=186)$ & $(\mathrm{N}=85)$ \\
\hline Overweight/obese classification matched $E^{2} R^{2 b}$ & 79.0 & 75.6 & 81.4 & 79.4 & 80.9 & 76.9 & 80.0 \\
\hline Child misclassified as not overweight/obese & 3.8 & 2.2 & 4.8 & 4.2 & 1.5 & 4.8 & 3.5 \\
\hline Child misclassified as overweight/obese & 17.2 & 22.2 & $13.8^{\mathrm{a}}$ & 16.4 & 17.6 & 18.3 & 16.5 \\
\hline Obesity classification matched $E H R^{2 b}$ & 81.9 & 80.0 & 83.2 & 87.3 & 80.9 & $78.5^{\mathrm{b}}$ & 78.8 \\
\hline Child misclassified as not obese & 3.4 & 2.2 & 4.2 & 3.2 & 4.4 & 3.2 & 2.4 \\
\hline Child misclassified as obese & 14.7 & 17.8 & 12.6 & 9.5 & 14.7 & $18.3^{b}$ & $18.8^{b}$ \\
\hline
\end{tabular}

EHR = Electronic health record; SD = Standard deviation around mean difference.

${ }^{1}$ Restricted to children with valid parent-reported data.

${ }^{2}$ Children with a BMI-for-age percentile $\geq 85$ were classified as overweight/obese and $\geq 95$ as obese.

${ }^{\text {a }}$ Significant difference between age groups by chi-square test $(P<.05)$.

${ }^{\mathrm{b}}$ Significantly different from nonHispanic Whites by chi-square test $(P<.05)$. 
the older versus younger children $(53.8 \%$ vs. $35.5 \%$, $P<.0001)$ and for Black versus nonHispanic White children $(55.9 \%$ vs. $40.8 \%, P<.05)$. Most errors were due to parent-based BMI-for-age percentiles $>5$ percentile points higher than the EHR. For the full sample $(\mathrm{n}=558)$ and across demographic subgroups, children were accurately classified as overweight/obese and obese based on parent-reported data approximately $80 \%$ of the time, with misclassification error more often due to children being classified as overweight/obese or obese based on parent-reported data when they were not.

Kappa statistics showed only moderate levels of agreement for overweight/obese (range 0.50-0.63) and obese (range 0.44-0.60) classifications based on parentreported and EHR data for the full sample and most subgroups (Table 3). For the overweight/obese classification, sensitivity ranged from the high 80 s to mid-90s, specificity from the high 60 s to mid-70s, and positive predictive values from the low 50s to mid-70s. For the obesity classification, sensitivity ranged from the mid70 s to mid-80s, specificity from the mid-70s to high 80 s, and positive predictive values from the low 40 s to low 60s. Positive predictive values for overweight/obese and obesity classifications were significantly higher for the 6 to 12 year olds than the 3 to 5 year olds.

Multivariable logistic regression models that included the child's race/ethnicity, age group, and sex were used to assess statistical significance of demographic differences in accuracy of height, weight, and overweight/ obese and obese classifications. Children aged 6 to 12 were significantly less likely than 3 to 5 year olds to have an accurately reported weight (OR $=0.47$, CI: $0.35-0.63$ ), but did not significantly differ from the younger children with regard to accuracy of height or overweight/obese and obese classifications. Boys were significantly less likely than girls to have an accurately reported height $(\mathrm{OR}=0.63, \mathrm{CI}: 0.46-0.87)$ and obese classification $(\mathrm{OR}=0.54, \mathrm{CI}: 0.35-0.84)$, but did not significantly differ in accuracy of reported weight or overweight/ obese classification. Compared to nonHispanic white children, Latino children were significantly less likely to have an accurately reported height $(\mathrm{OR}=0.67$, CI: 0.45-0.99), weight ( $\mathrm{OR}=0.69, \mathrm{CI}: 0.46-0.98)$, and obese classification (OR $=0.55$, CI: $0.31-0.95)$, but did not significantly differ on overweight/obese classification. Accuracy of parent-reported height and weight data and overweight/obese and obese classification for Black and Asian children was not significantly different from nonHispanic Whites. The strength of association of these demographic factors with accuracy was not mediated by parent sex (same or opposite child sex) or recentness of the parent learning their child's height/weight. However, accuracy of parent reported weight and height was significantly lower when parents last learned their child's

Table 3 Accuracy and validity of child overweight and obesity classification based on parent-reported data as compared to electronic health record data

\begin{tabular}{|c|c|c|c|c|c|c|c|}
\hline \multirow{4}{*}{ Weight classification } & \multirow[b]{2}{*}{ All } & \multicolumn{2}{|c|}{ By child Age } & \multicolumn{4}{|c|}{ By child race/ethnicity } \\
\hline & & Ages 3-5 y & Ages 6-12 y & $\begin{array}{l}\text { NonHispanic } \\
\text { White }\end{array}$ & Black & Latino & Asian \\
\hline & $(\mathrm{N}=558)$ & $(\mathrm{N}=225)$ & $(\mathrm{N}=333)$ & $(N=189)$ & $(N=68)$ & $(\mathrm{N}=186)$ & $(\mathrm{N}=85)$ \\
\hline & $\%(95 \% \mathrm{Cl})$ & $\%(95 \% \mathrm{Cl})$ & $\%(95 \% \mathrm{Cl})$ & $\%(95 \% \mathrm{Cl})$ & $\%(95 \% \mathrm{Cl})$ & $\%(95 \% \mathrm{Cl})$ & $\%(95 \% \mathrm{Cl})$ \\
\hline \multicolumn{8}{|l|}{$\begin{array}{l}\text { Overweight/obese (BMI- } \\
\text { for-age percentile } \geq 85 \text { ) }\end{array}$} \\
\hline Kappa & $0.58(0.53-0.63)$ & $0.50(0.39-0.55)$ & $0.63(0.54-0.70)$ & $0.57(0.44-0.66)$ & $0.63(0.41-0.68)$ & $0.55(0.42-0.64)$ & $0.60(0.39-0.70)$ \\
\hline Sensitivity & 89.8 (85.3-93.2) & 91.7 (82.1-96.8) & 89.0 (83.7-93.0) & 86.7 (76.8-93.3) & 96.4 (82.9-99.8) & $88.9(81.3-94.2)$ & $90.0(75.6-97.3)$ \\
\hline Specificity & $72.8(70.2-74.8)$ & $69.7(66.2-71.6)$ & $75.5(71.5-78.6)$ & $76.0(71.4-79.1)$ & $70.0(60.5-72.4)$ & $67.6(61.8-71.7)$ & $74.5(66.7-78.5)$ \\
\hline $\begin{array}{l}\text { Positive predictive } \\
\text { value }\end{array}$ & $65.7(62.5-68.2)$ & $52.4(46.9-55.3)$ & $73.7^{\mathrm{a}}(69.4-77.0)$ & $62.7(55.5-67.5)$ & $69.2(59.5-71.7)$ & $67.9(62.2-71.9)$ & $65.9(55.3-71.2)$ \\
\hline \multicolumn{8}{|c|}{$\begin{array}{l}\text { Obese } \\
\text { (BMl-for-age percentile } \geq 95 \text { ) }\end{array}$} \\
\hline Kappa & $0.54(0.47-0.60)$ & $0.44(0.31-0.51)$ & $0.60(0.50-0.68)$ & $0.56(0.39-0.68)$ & $0.55(0.30-0.69)$ & $0.53(0.40-0.61)$ & $0.48(0.26-0.58)$ \\
\hline Sensitivity & 83.6 (76.4-89.3) & $84.4(68.1-94.0)$ & $83.3(74.9-89.7)$ & 78.6 (61.1-90.4) & 84.2 (63.4-95.6) & 87.8 (76.4-94.7) & 87.5 (63.4-97.8) \\
\hline Specificity & $81.4^{c}(79.5-82.9)$ & $79.3^{c}(76.6-80.9)$ & $83.1^{\mathrm{C}}(80.3-85.3)$ & $88.3^{c}(85.3-90.3)$ & $78.0^{\mathrm{b}}(70.1-82.3)$ & $75.2^{\mathrm{b}}(71.1-77.7)$ & 76.8 (71.2-79.2) \\
\hline $\begin{array}{l}\text { Positive predictive } \\
\text { value }\end{array}$ & $54.2^{\complement}(49.5-57.8)$ & $40.3^{c}(32.5-44.9)$ & $62.5^{\mathrm{ac}}(56.2-67.3)$ & 53.7 (41.7-61.8) & $59.3(44.6-67.3)$ & $55.8^{c}(48.6-60.3)$ & $46.7^{c}(33.8-52.1)$ \\
\hline
\end{tabular}

Notes: All analyses restricted to children with data from both sources; $\mathrm{Cl}=$ Confidence interval; Kappa statistic is not a percentage.

${ }^{a}$ Significant difference between age groups by $t$-test $(P<.05)$.

${ }^{\mathrm{b}}$ Significantly different from nonHispanic Whites by $t$-test $(P<.05)$.

'Significantly different from same statistic for Overweight/obese by $t$-test $(P<.05)$. 
measurements $>7$ days vs. $\leq 7$ days before the survey $(\mathrm{OR}=0.30, \mathrm{CI}: 0.21-0.44$ for weight and $\mathrm{OR}=0.26$, CI: $0.17-0.41$ for height).

\section{Prevalence of overweight/obesity and obesity based on EHR and parent-reported data}

For the full sample and most subgroup comparisons, there were significant differences (15 percentage points on average) in prevalence of overweight/obesity and obesity based on parent-reported data for those children with usable BMI-for-age percentile data versus EHR data for all children in the sample (Table 4). Based on EHR data for the full sample, $35.2 \%$ of the children were classified as overweight/obese, with $19.4 \%$ in the obese range, compared with significantly higher prevalence of $50.2 \%$ and $32.1 \%$, respectively, using parent-reported data. EHR data indicated that children aged 6 to 12 were significantly more likely than 3 to 5 year olds to be overweight/obese ( $41 \%$ vs. $27 \%, P<.0001)$ and obese $(23.6 \%$ vs. $13.4 \%, P<.0001)$, but prevalence differences by age group were not as large or statistically significant when parent-reported data were used $(52.5 \%$ vs. $46.7 \%$ overweight/obese, $33.6 \%$ vs. $29.8 \%$ obese). Comparisons of overweight/obesity and obesity across race-ethnic groups generally showed smaller differences in point prevalence between EHR data and parent-reported data, in some instances resulting in race-ethnic differences being statistically significant only using parent-reported data. For example, Latinos were significantly more likely to be overweight/obese and obese than nonHispanic Whites based on both data sources, but differences between nonHispanic Whites and Blacks were significant for obesity based only on parent-reported data.

\section{Parent perception of child being overweight}

Data about parent perception of whether the child was of normal weight, overweight, or very overweight was available for nearly all children. The percentages of children whose parents thought they were overweight $(14.0 \%)$ or very overweight $(1.0 \%)$ were significantly lower than the percentages with those weight classifications based on EHR data (Figure 1). This was true across age and race-ethnic groups. Children aged 6 to 12 years were significantly more likely than 3 to 5 year olds to be perceived by parents as overweight $(20.5 \%$ vs. $4.6 \%$, $P<.0001)$, and Latinos and Asians were significantly more likely to be perceived as overweight than nonHispanic Whites ( $15.6 \%$ and $15.7 \%$ vs. $11.6 \%$, respectively), with no significant difference by child sex. Only $61.4 \%$ (121/197) of children classified as obese (EHR BMI-for-age percentile $\geq 95$ ) were considered by their parent to be overweight, with children in the older age group significantly more likely $(\mathrm{OR}=5.38$, CI 2.75-10.52) to be considered overweight than the younger children and no significant difference by child race/ethnicity or sex.

\section{Effect of missing parent-reported data on estimated prevalence of overweight and obesity}

Due to the large number of children for whom a weight classification could not be assigned based on parentreported data, we re-estimated the prevalence of overweight/obesity and obesity using parent-reported data weighted to reflect the age and gender counts for each race-ethnic group in the full sample. These new prevalence estimates for the full sample and for each demographic group (not shown) were nearly identical to those produced with the unweighted data, suggesting no bias.

Table 4 Prevalence of child overweight and obesity based on electronic health record and parent-reported data

\begin{tabular}{|c|c|c|c|c|c|c|c|}
\hline & \multirow[b]{2}{*}{ All } & \multicolumn{2}{|c|}{ By child age } & \multicolumn{4}{|c|}{ By child race/ethnicity } \\
\hline & & Ages 3-5 y & Ages 6-12 y & $\begin{array}{c}\text { NonHispanic } \\
\text { White }\end{array}$ & Black & Latino & Asian \\
\hline & $\%(95 \% \mathrm{Cl})$ & $\%(95 \% \mathrm{Cl})$ & $\%(95 \% \mathrm{Cl})$ & $\%(95 \% \mathrm{Cl})$ & $\%(95 \% \mathrm{Cl})$ & $\%(95 \% \mathrm{Cl})$ & $\%(95 \% \mathrm{Cl})$ \\
\hline \multicolumn{8}{|c|}{ Overweight/obese (BMl- for-age percentile $\geq 85$ ) } \\
\hline $\begin{array}{l}\text { EHR data for full } \\
\text { sample }\end{array}$ & $35.2(32.3-38.1)$ & $27.0(22.8-31.1)$ & $41.0^{\mathrm{a}}(37.1-44.9)$ & $29.7(24.3-35.1)$ & $31.9(23.3-40.5)$ & $42.8^{b}(38.0-47.6)$ & $32.0(25.4-38.5)$ \\
\hline $\begin{array}{l}\text { Parent-reported } \\
\text { data }\end{array}$ & $50.2^{c}(46.0-54.3)$ & $46.7^{\mathrm{C}}(40.1-53.2)$ & $52.5^{a}(47.2-57.9)$ & $43.9^{c}(36.8-51.1)$ & $57.4^{c}(45.3-69.4)$ & $57.0^{\mathrm{cb}}(49.8-64.2)$ & $48.2(37.4-59.1)$ \\
\hline \multicolumn{8}{|c|}{ Obese (BMI-for-age percentile $\geq 95$ ) } \\
\hline $\begin{array}{l}\text { EHR data for full } \\
\text { sample }\end{array}$ & 19.4 (17.0-21.8) & $13.4(10.1-16.6)$ & $23.6^{a}(20.2-26.9)$ & $14.4(10.3-18.7)$ & $18.1(11.0-25.2)$ & $23.7^{b}(19.6-27.9)$ & $19.3(13.8-24.8)$ \\
\hline $\begin{array}{l}\text { Parent-reported } \\
\text { data }\end{array}$ & $32.1^{c}(28.2-36.0)$ & $29.8^{c}(23.7-35.8)$ & $33.6^{c}(28.5-38.7)$ & $21.6^{c}(15.7-27.5)$ & $39.1^{\text {bc }}(27.3-50.9)$ & $41.4 b^{b c}(34.2-48.5)$ & $35.3^{b c}(25.1-45.5)$ \\
\hline
\end{tabular}

EHR = Electronic health record; $\mathrm{Cl}=$ Confidence interval around percentage.

Denominators for full sample/children with parent-reported weight classification: All: $N=1053 / 558$; Ages 3 to 5 : $N=434 / 225 ;$ Ages 6 to 12 : $N=619 / 333$.

NonHispanic Whites: N = 276/180; Blacks: N =116/69; Latinos N = 409/186; Asians N = 197/85.

${ }^{\mathrm{a}}$ Significant difference between age groups by two-tailed $z$-test $(P<.05)$.

${ }^{\mathrm{b}}$ Significantly different from nonHispanic Whites by two-tailed $z$-test $(P<.05)$.

'Significant difference between prevalence estimated from parent-reported data and EHR data for all children in the demographic group by two-tailed z-test $(P<.05)$. 


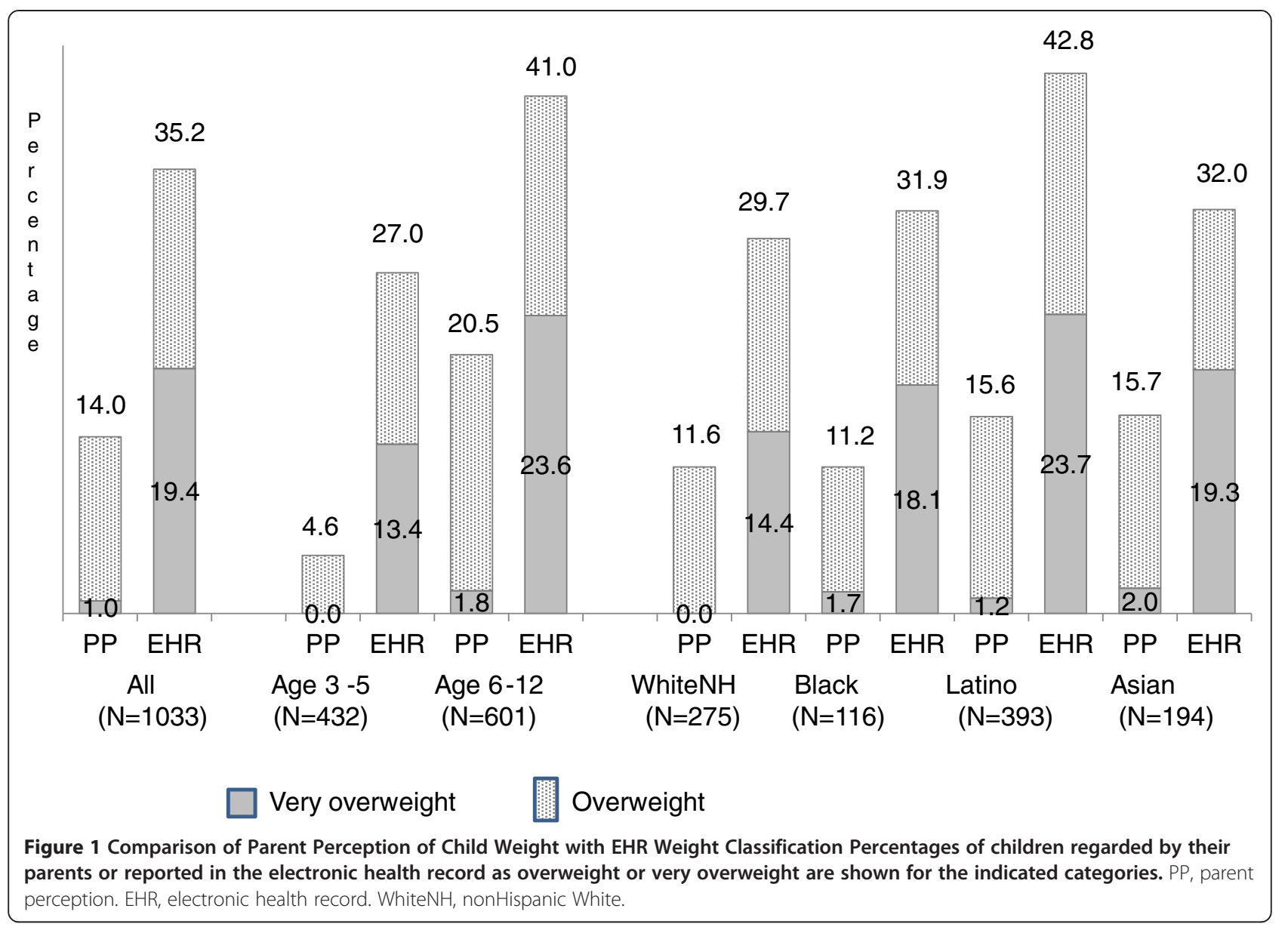

We also compared children with and without parent-reported weight classification data on the following factors: whether height, weight, or both measures were unavailable; child weight classification status based on EHR; parent perception that the child is overweight; child sex; child age group; and length of time since child's weight and height were last measured (Table 5). Black children missing a parent-reported weight classification were significantly less likely than those who had one to be classified based on EHR data as overweight/obese and to have their parent think they are overweight. For other demographic subgroups, EHR-based classification as overweight/obese and parent perception that their child was overweight did not significantly differ between children with and without parent-reported weight classification data. Across all demographic subgroups, with the exception of Black children, parents of children without a parent-reported weight classification were significantly more likely than those with one to indicate that it had been more than 6 months since they last learned their child's height and weight.

\section{Availability of tools in the home to measure height and weight}

Approximately $70 \%$ of the households had a scale and $74 \%$ a tape measure or yardstick (Table 6). However, only $58 \%$ had both of these tools, and $14 \%$ had neither. While the availability of these tools in the home did not significantly differ by age group, parents of Black and Latino children were significantly less likely than parents of nonHispanic White and Asian children to report having them.

\section{Discussion}

In this study of parents' ability to accurately estimate their children's height and weight, only $49 \%$ of parents who reported their child's height and 58\% who reported their child's weight in a clinic waiting room survey provided information that matched their child's height within 1 inch and weight within 2 lbs. Similar to O'Connor and Gugenheim's clinic based survey [12], Latino children in our clinic-based survey were significantly less likely than nonHispanic White children to have parentreported height and weight data at this level of accuracy. Children aged 6 to 12 were also significantly less likely 
Table 5 Comparison of children with and missing overweight and obesity classifications based on parent-reported data

\begin{tabular}{|c|c|c|c|c|c|c|c|c|c|c|c|c|c|c|}
\hline & & & \multicolumn{4}{|c|}{ By child age } & \multicolumn{8}{|c|}{ By child race/ethnicity } \\
\hline & \multicolumn{2}{|c|}{ All } & \multicolumn{2}{|c|}{ Ages 3-5 y } & \multicolumn{2}{|c|}{ Ages 6-12 y } & \multicolumn{2}{|c|}{$\begin{array}{l}\text { NonHispanic } \\
\text { White }\end{array}$} & \multicolumn{2}{|c|}{ Black } & \multicolumn{2}{|c|}{ Latino } & \multicolumn{2}{|c|}{ Asian } \\
\hline & PR & No PR & PR & No PR & PR & & PR & No PR & PR & No PR & PR & & PR & No PR \\
\hline & $(\mathrm{N}=558)$ & $(\mathrm{N}=495)$ & $(\mathrm{N}=225)$ & $(N=209)$ & $(\mathbf{N}=333)$ & $(\mathrm{N}=\mathbf{2 8 6})$ & $(\mathrm{N}=189)$ & $(N=87)$ & $(N=68)$ & $(\mathrm{N}=48)$ & $(\mathrm{N}=223)$ & $(\mathrm{N}=186)$ & $(\mathrm{N}=85)$ & $(\mathrm{N}=112)$ \\
\hline & $\%$ & $\%$ & $\%$ & $\%$ & $\%$ & $\%$ & $\%$ & $\%$ & $\%$ & $\%$ & $\%$ & $\%$ & $\%$ & $\%$ \\
\hline \multicolumn{15}{|l|}{$\begin{array}{l}\text { EHR weight } \\
\text { classification }\end{array}$} \\
\hline $\begin{array}{l}\text { Overweight/ } \\
\text { obese }\end{array}$ & 36.7 & 33.5 & 26.7 & 27.3 & 43.5 & 38.1 & 31.7 & 25.3 & 41.2 & $18.8^{\mathrm{a}}$ & 43.5 & 42.2 & 35.3 & 29.5 \\
\hline Obese & 20.8 & 17.8 & 14.2 & 12.4 & 25.2 & 21.7 & 14.8 & 13.8 & 27.9 & $4.2^{\mathrm{a}}$ & 26.3 & 21.5 & 18.8 & 19.6 \\
\hline $\begin{array}{l}\text { Parent thinks } \\
\text { child is } \\
\text { overweight }\end{array}$ & 17.2 & 10.8 & 4.9 & 4.3 & 25.8 & $15.6^{\mathrm{a}}$ & 14.8 & $4.6^{\mathrm{a}}$ & 16.2 & $4.2^{\mathrm{a}}$ & 19.4 & 13.6 & 21.4 & 11.8 \\
\hline Child is a boy & 48.9 & 50.5 & 47.6 & 49.3 & 49.9 & 51.4 & 47.6 & 54.0 & 36.8 & 54.2 & 54.8 & 45.7 & 48.2 & 55.4 \\
\hline $\begin{array}{l}\text { Mean age } \\
\text { (SD) of } \\
\text { children }\end{array}$ & $7.5(3.1)$ & $6.9^{\mathrm{a}}(2.7)$ & $4.3(0.8)$ & $4.3(0.9)$ & $9.7(1.9)$ & $8.8^{\mathrm{a}}(1.9)$ & $7.3(3.1)$ & $7.1(2.5)$ & $7.9(3.0)$ & $6.8(2.8)$ & $7.7(3.1)$ & $7.2(2.8)$ & $7.4(3.1)$ & $6.4^{*}(2.6)$ \\
\hline \multicolumn{15}{|l|}{$\begin{array}{l}\text { How recently } \\
\text { child was } \\
\text { measured }\end{array}$} \\
\hline $\begin{array}{c}\text { Weight }> \\
6 \text { months ago }\end{array}$ & 11.6 & $28.2^{\mathrm{a}}$ & 9.9 & $19.1^{\mathrm{a}}$ & 12.7 & $34.9^{\mathrm{a}}$ & 9.7 & $22.1^{\mathrm{a}}$ & 15.2 & 27.7 & 12.4 & $32.3^{\mathrm{a}}$ & 9.4 & $25.0^{\mathrm{a}}$ \\
\hline $\begin{array}{c}\text { Height }> \\
6 \text { months ago }\end{array}$ & 18.3 & $43.0^{\mathrm{a}}$ & 15.1 & $32.7^{\mathrm{a}}$ & 20.6 & $50.7^{\mathrm{a}}$ & 14.7 & $33.3^{\mathrm{a}}$ & 26.9 & 32.6 & 17.7 & $44.8^{\mathrm{a}}$ & 17.6 & $42.9^{a}$ \\
\hline $\begin{array}{l}\text { Mother } \\
\text { completed } \\
\text { questionnaire }\end{array}$ & 82.6 & 86.8 & 80.8 & 87.6 & 83.8 & 86.3 & 79.3 & 82.8 & 85.3 & 93.7 & 86.6 & 91.9 & 81.2 & 75.9 \\
\hline
\end{tabular}

EHR = Electronic health record; PR = Has weight classification based on parent-reported data; No PR = Missing weight classification based on parent-reported data. ${ }^{a}$ Significant difference $(P<.05)$ between PR and No PR for this demographic subgroup by chi-square test.

than those aged 3 to 5 to have accurately reported weight. Our study, in line with several previous studies $[4,5,12,13]$, found that inaccurate parent-reported weight was more often a result of underestimation than overestimation. However, in contrast to many studies but similar to those of O'Connor and Gugenheim [12] and
Shields et al. [13], we found that inaccurate parentreported height was more likely to result from underestimation than overestimation. Our finding that misclassification of children as obese based on parent-report was associated with underestimation of height is in line with Shields et al. [13].

Table 6 Availability of tools to measure height and weight at home

\begin{tabular}{|c|c|c|c|c|c|c|c|}
\hline & \multirow[b]{2}{*}{ All } & \multicolumn{2}{|c|}{ By child age } & \multicolumn{4}{|c|}{ By child race/ethnicity } \\
\hline & & Ages 3-5 y & Ages 6-12 y & $\begin{array}{l}\text { NonHispanic } \\
\text { White }\end{array}$ & Black & Latino & Asian \\
\hline & $(\mathrm{N}=1051)$ & $(\mathrm{N}=433)$ & $(\mathrm{N}=618)$ & $(N=276)$ & $(N=116)$ & $(\mathrm{N}=407)$ & $(\mathrm{N}=197)$ \\
\hline & $\%(95 \% \mathrm{Cl})$ & $\%(95 \% \mathrm{Cl})$ & $\%(95 \% \mathrm{Cl})$ & $\%(95 \% \mathrm{Cl})$ & $\%(95 \% \mathrm{Cl})$ & $\%(95 \% \mathrm{Cl})$ & $\%(95 \% \mathrm{Cl})$ \\
\hline Scale & $69.9(67.1-72.7)$ & $71.1(66.8-75.4)$ & $68.2(65.3-72.6)$ & $76.1(71.0-81.2)$ & $56.0^{a}(46.9-65.2)$ & $60.9^{a}(56.2-65.7)$ & $82.7(77.4-88.1)$ \\
\hline Tape measure or yardstick & $73.8(71.1-76.5)$ & $76.0(71.9-80.0)$ & $72.0(68.5-75.6)$ & $86.6(82.6-90.6)$ & $65.5^{\mathrm{a}}(56.8-74.3)$ & $61.2^{\mathrm{a}}(56.5-66.0)$ & $83.7(78.5-88.9)$ \\
\hline $\begin{array}{l}\text { Both scale and height } \\
\text { measuring tool }\end{array}$ & $57.8(54.9-60.8)$ & $61.0(56.4-65.6)$ & $55.7(51.7-59.6)$ & $71.0(65.6-76.4)$ & $44.0^{\mathrm{a}}(34.8-53.1)$ & $44.5^{\mathrm{a}}(39.6-49.3)$ & $73.1(66.8-79.3)$ \\
\hline $\begin{array}{l}\text { No tool to measure weight } \\
\text { or height }\end{array}$ & $14.3(12.1-16.4)$ & $13.6(10.4-16.9)$ & $14.7(11.9-17.5)$ & $8.3(5.1-11.6)$ & $22.4^{\mathrm{a}}(14.7-30.1)$ & $21.4^{\mathrm{a}}(17.4-25.4)$ & $6.5(3.1-10.1)$ \\
\hline
\end{tabular}


Approximately $40 \%$ of parents did not attempt to estimate their child's height, about $25 \%$ did not attempt to estimate their child's weight, and fewer than half of the parents provided sufficient information to classify their child's weight. With the exception of Black children, the percentages of children with and without usable BMIfor-age percentile information from parent reports were similar for overweight/obese and obese classifications based on their EHR. As a consequence, similar to O'Connor and Gugenheim [12], we observed no bias due to missing data for this sample with regard to estimates of overweight/obesity or obesity based on parentreported data. However, because Black children who were missing parent-reported weight classification data were significantly less likely to be overweight/obese than those without missing data, if the proportion of Black children in the sample had been much larger, there would have been greater potential for bias due to missing data.

As many other studies have found [4,5,7-9,11-15], prevalence of overweight/obesity and obesity among these pre-school and pre-adolescent children based on parent-reported data of height and weight was significantly higher than prevalence based on actual measurements. Similar to the Akinbami and Ogden study that showed larger differences between obesity estimates based on parent-reported versus interviewer-measured height and weight for Black and Mexican-American children than nonHispanic White children [4], we found larger differences for Blacks, Latinos, and Asians than for nonHispanic Whites in prevalence of obesity, but not overweight/obesity, based on parent-reported and EHR data. Despite this overestimation of BMI from height and weight reports, a majority of our parents did not recognize that their child was overweight, consistent with the findings of other studies [21-24]. We found that this misperception was greater for younger than older children, but did not appear to differ by race or ethnicity. We also found that accuracy of parental perception of their child being overweight did not significantly differ for parents who did or did not report usable height and weight data for their children.

Our study adds to knowledge about factors associated with accuracy and availability of parent-reported information about child height and weight. We found that in this clinic-based sample, the source of the parental report (mother vs. father) did not affect accuracy, whether the child was of the same sex or opposite sex of the parent. However, accuracy was significantly associated with length of time since the parent had learned their child's height and weight, and decrease in accuracy was not linear with time, having the biggest drop off after 7 days. We also found that while parents of Latino, Black, and Asian children were significantly less likely than parents of nonHispanic White children to be able to report their child's height and weight, accuracy of parent-reported data only differed significantly for Latino children.

We found that only approximately $70 \%$ of the parents in our study have sufficient equipment at home to measure weight and height, with significant variation according to race/ethnic groups. This reveals the difficulty in asking parents to obtain and provide accurate data using a scale and tape measure for surveillance, research, and program evaluation if these tools are not provided for this purpose.

A strength of our study is that parent-reported height and weight data and clinic-measured data were obtained on the same day and linked at the individual child level. Because we had EHR data for all children, we were able to compare overweight/obesity and obesity prevalence based on parent-reported data versus measured height and weight data for the whole study population rather than just the subgroup of children who had data from both sources. We examined factors associated with accuracy and unavailability of parent-reported data and showed that length of time since parent last learned the child's height and weight is the main factor contributing to inaccuracy and lack of reporting. Finally, we described the availability of tools in the home to measure height and weight, showing that less than two-thirds of parents of Black and Latino children reported having a scale at home and approximately one in five a scale or tape measure/yardstick. The large percentage of families lacking a scale at home suggests that researchers and pediatricians should not assume that most parents with overweight and obese children currently have sufficient tools to monitor their child's weight at home.

The main limitation of this study is the large percentage of children whose parents did not provide usable height and weight data. We used the situation that approximately half of the children did not have a usable BMI-for-age percentile to classify them as overweight/ obese or obese as an opportunity to examine the issue of potential bias introduced by missing data. However, missing data affected our ability to assess accuracy of parent-report compared to the EHR, especially for the Black and Asian subgroups. The small size of our Latino, Black, and Asian subgroups with parent-reported data also limited our ability to assess differences in accuracy by child sex and age within race/ethnic group. Because our results are based on samples of patients seen in three pediatric clinics of a large Northern California health plan, the racial and ethnic composition of the sample may not be generalizable to other populations. Finally, while we used the EHR as our "gold standard" for height and weight, we cannot be sure that all measurements were taken and recorded accurately by the clinic medical assistants. 


\section{Conclusions}

In this study, use of parent-reported height and weight data overestimated the prevalence of childhood overweight/obesity and obesity compared to clinic-measured data. Due to cost and logistical constraints it may not be possible to base estimates of overweight and obesity prevalence for national, state, or local initiatives on recently measured height and weight data, but our results add to a growing number of studies that recommend that parent-reported data not be used to estimate prevalence of overweight/obesity and obesity among preschool and elementary school aged children.

\section{Additional file}

Additional file 1: Survey Questionnaire.

\section{Competing interests}

The authors declare they have no competing interests.

\section{Authors' contributions}

NPG conceived and designed the study, conducted the literature review, and had overall responsibility for data collection and data analysis. RGM helped develop the survey data collection protocol, was responsible for data collection at the Stockton site, and recruited the other two study sites. NPG and RGM collaborated on the interpretation of the results and writing of the manuscript. Both authors read and approved the final manuscript.

\section{Authors' information}

NPG is a Research Scientist at Kaiser Permanente Northern California's Division of Research in Oakland, CA. RGM is Chief of Pediatrics for Kaiser Permanente Northern California's Central Valley Area.

\section{Acknowledgements}

This study was funded by Kaiser Permanente Northern California Region's Community Benefit Program. We want to acknowledge the major contribution of Dr. Kellie Kute, Chief of Pediatrics for Kaiser Permanente Vallejo and Fairfield, and the Pediatric Department receptionists and medical assistants at the Stockton, Vallejo, and Fairfield medical facilities who participated in the data collection for this study. We also want to acknowledge the analytic review provided by our consulting biostatistician, Dr. Yun-Yi Hung.

\section{Author details}

${ }^{1}$ Division of Research, Kaiser Permanente Medical Care Program, 2000 Broadway, Oakland, CA 94611, USA. ${ }^{2}$ Department of Pediatrics, Kaiser Permanente Northern California Central Valley Area, Stockton, CA, USA.

Received: 20 January 2014 Accepted: 22 January 2015

Published online: 12 February 2015

\section{References}

1. Must A, Strauss RS. Risks and consequences of childhood and adolescent obesity. Int J Obesity. 1999;23 Suppl 2:s2-11.

2. Trasande $L$, Elbel $B$. The economic burden placed on healthcare systems by childhood obesity. Expert Rev Pharmacoecon Outcomes Res. 2012;12(1):39-45.

3. Ogden CL, Carroll MD, Kit BK, Flegal KM. Prevalence of obesity and trends in body mass index among US children and adolescents, 1999-2010. JAMA. 2012;307(5):483-90.

4. Akinbami $\sqcup$, Ogden CL. Childhood overweight prevalence in the United States: The impact of parent-reported height and weight. Obesity. 2009;16:1574-80

5. Huybrechts I, De Baquer D, Van Trimpont I, De Backer G, De Henauw S. Validity of parentally reported weight and height for preschool-aged children in
Belgium and its impact on classification into body mass index categories. Pediatrics. 2006;118:2109-18

6. Scholtens S, Brunekreef B, Visscher TL, Smit HA, Kerkhof M, de Jongste JC, et al. Reported versus measured body weight and height of 4-year-old children and the prevalence of overweight. Eur J Public Health. 2007;17:369-74.

7. Banach A, Wade TJ, Cairney J, Hay JA, Faught BE, O'Leary DD. Comparison of anthropomometry and parent-reported height and weight among nine year olds. Can J Public Health. 2007;98(4):251-3.

8. Skinner AC, Miles D, Perrin EM, Coyne-Beasley T, Ford C. Source of parental reports of child height and weight during phone interviews and influence on obesity prevalence estimates among children aged 3-17 years. Public Health Rep. 2013;128(1):46-53.

9. Brettschneider AK, Ellert U, Rosario AS. Comparison of BMI derived from parent-reported height and weight with measured values: Results from the German KiGGS Study. Int J Environ Res Public Health. 2012;9:632-47.

10. Davis H, Gergen PJ. Mexican-American mothers' reports of the weights and heights of children 6 months through 11 years old. J Am Diet Assoc. 1994;94:512-6.

11. Dubois L, Girad M. Accuracy of maternal reports of pre-schoolers' weights and heights as estimates of BMI values. Int J Epidemiol. 2007;36:132-8.

12. O'Connor DP, Gugenheim JJ. Comparison of measured and parents'reported height and weight in children and adolescents. Obesity. 2011;19(5):1040-6.

13. Shields M, Gorber SC, Janssen I, Tremblay MS. Obesity estimates for children based on parent-reported versus direct measures. Health Rep. 2011;22(3):47-58.

14. Garcia-Marcos L, Valverde-Molina J, Sanchez-Solis M, Soriano-Pérez MJ, Baeza-Alcaraz A, Martinez-Torres A, et al. Validity of parent-reported height and weight for defining obesity among asthmatic and nonasthmatic schoolchildren. Int Arch Allergy Immunol. 2006;139(2):139-45.

15. Sekine M, Yamagami T, Hamanishi S, Kagamimori S. Accuracy of the estimated prevalence of childhood obesity from height and weight values reported by parents: results of the Toyama Birth Cohort Study. J Epidemiol. 2002;12:9-13.

16. Centers for Disease Control. A SAS program for the CDC growth charts. Available at: http://www.cdc.gov/nccdphp/dnpao/growthcharts/resources/ sas.htm

17. Altman DG. Practical statistics for medical research. London: Chapman and Hall; 1991.

18. Kreuter F, Valliant R. A survey on survey statistics: What is done and can be done in Stata. Stata J. 2007;7(1):1-21.

19. StatPages.org. 2-way contingency table analysis. Available at http://statpages. org/ctab2 2 .html.

20. Institute SAS. Inc. SAS/STAT 9.3 User's Guide. Cary. SAS Institute Inc: NC; 2011.

21. Chaimovitz R, Issenman R, Moffat T, Persad R. Body perception: do parents, their children, and their children's physicians perceive body image differently? J Pediatr Gastroenterol Nutr. 2008;47(1):76-80.

22. Meizi H, Evans A. Are parents aware that their children are overweight or obese? Do they care? Can Fam Physician. 2007:53(9):1493-9.

23. Eckstein KC, Mikhail LM, Ariza AJ, Thomson S, Millard SC, Binns HJ. Parents' perceptions of their child's weight and health. Pediatrics. 2006;117(3):681-90.

24. Carnell S, Edwards C, Croker H, Boniface D, Wardle J. Parental perceptions of overweight in 3-5 y olds. Int J Obes Relat Metab Disord. 2005;29:353-5.

\section{Submit your next manuscript to BioMed Central and take full advantage of:}

- Convenient online submission

- Thorough peer review

- No space constraints or color figure charges

- Immediate publication on acceptance

- Inclusion in PubMed, CAS, Scopus and Google Scholar

- Research which is freely available for redistribution 